\title{
Era uma vez, para a alma: uma revisão dos efeitos do storytelling* nas tradições religiosas
}

J. D. Sunwolf, $\mathrm{PhD}$

Departamento de Comunicações, Universidade Santa Clara.

E-mail: sunwolf@scu.edu

Na África Ocidental, quando uma pessoa da aldeia adoece, o curandeiro pergunta-lhe: "Quando foi a última vez que você cantou? Quando foi a última vez que você dançou? Quando foi a última vez que você contou uma história?”.

$\operatorname{Cox}^{1}$

Agora, às vezes Deus cansa de deixar as pessoas felizes e sempre mistura um pouco de azar com a boa sorte, como a chuva com o sol. A rainha sentiu-se mal, mas nem os doutos médicos nem os curandeiros podiam fazer qualquer coisa por ela.

Donkeyskin, de uma lenda popular oral

\section{HOMO NARRANS: HISTÓRIAS DA MENTE E DA ALMA}

Entre o povo, que sabe dessas coisas, diz-se que o primeiro contador de histórias, à noite, se aproximou dos deuses e ficou ouvindo-os falar enquanto dormiam - assim, todos os contos que o contador colecionou continham o fôlego dos deuses. Seres humanos são criaturas que contam histórias. De fato, estes foram descritos por MacIntyre ${ }^{2}$ como animais que contam histórias. As pessoas têm necessidade de possuir símbolos que as ajudem a entender e a interpretar o mundo. Fisher ${ }^{3}$, um estudioso que colocou os sistemas de narrativa em primeiro plano para a compreensão da comunicação, sugeriu que o ser humano pode ser mais bem entendido como homo narrans, pois organizamos nossas experiências em histórias que têm tramas, personagens centrais e seqüências de ação que

\footnotetext{
* $\mathrm{O}$ ato de contar histórias. [N.E.]

1. $\operatorname{COX}, A$. A journey down the healing path through story (Uma viagem pelo caminho curativo da história). Diving in the Moon, 1, 10-23, 2000.

2. MacINTYRE, A. After virtue: a study in moral theory (Após a virtude: um estudo em teoria moral). 2. ed. Notre Dame: University of Notre Dame Press, Paris, 1981.

3. FISHER, W. R. The narrative paradigm: in
} 
the beginning. Journal of Communication, 35(4), 74-89, 1985. Id. Human communication as narration: toward a philosophy of reason, value, and action (Comunicação humana como narração: para uma filosofia da razão, valor e ação). Columbia: Press University of South Carolina, 1987.

4. FISHER, W. R. The narrative..., op. cit.

5. SARBIN, T. R. Narrative psychology: the storied nature of human conduct (Psicologia narrativa: a natureza da conduta humana contada). New York: Praeger, 1986

6. SUNWOLF, J. D. The pedagogical and persuasive effects of Native American lesson stories, African dilemma tales, and Sufi wisdom tales (Os efeitos pedagógicos e persuasivos de histórias moralizantes americanas nativas, contos de dilema africanos e contos de sabedoria Sufi). Howard Journal of Communications, 10, 47-71, 1999

7. Id. Grief tales: the therapeutic power of folktales to heal bereavement and loss. (Contos de tristeza: o poder terapêutico de contos folclóricos para curar luto e perda). Diving in the Moon, Honoring Story, Facilitating Healing, 4, 36-42, 2003.

8. CAMPBELL, A. F., sj. The storyteller's role: reported story and biblical text $(\mathrm{O}$ papel do contador de histórias: história contada e texto bíblico). The Catholic Biblical Quarterly, v. 64, 427-441, 2002.

9. NIDITH, S. Oral world and written word: ancient israelite literature (Mundo oral e palavra escrita: literatura israelita antiga). Louisville, Westminster: John Knox Press, 1996.

10. CANDA, E. R. Spirituality, religious diversity, and social work practice trazem lições implícitas e explícitas. Se, como argumentou Fisher, as pessoas buscam instintivamente uma lógica narrativa, e todos os seres humanos são em essência contadores de histórias, então compartilhá-las é uma ferramenta poderosa para ajudar a conferir sentido a valores espirituais, dividir essas crenças com outros e, assim, entender profundamente suas próprias mentes e almas.

As histórias estão entre nossas unidades mais básicas de comunicação. Somos socializados através da narratividade, embora possamos ser educados por meio da racionalidade ${ }^{4}$. O papel das histórias, sob uma perspectiva social, foi analisado em campos tão diversos como psicologia, sociolingüística, ciências políticas, história, antropologia, direito e comunicações. Os seres humanos pensam, percebem, imaginam e fazem escolhas morais de acordo com as estruturas narrativas ${ }^{5}$.

Ainda que os efeitos de compartilhar narrativas visando à transmissão de cultura entre crianças em ambientes educacionais e entre aqueles que estão doentes tenham sido bem documentados, pouca atenção acadêmica direciona-se à questão de como ouvir narrativas afeta os membros de tradições e comunidades espirituais. Os próprios contadores de histórias, entretanto, há muito tempo reconhecem o poder de as narrativas transportarem os ouvintes do momento da dor a um "e todos viveram felizes para sempre" ${ }^{6}$, com poderosos relatos provocando intensos flashes de introspecção para os ouvintes com necessidades, físicas ou espirituais. Desespero, trauma, doenças e luto criam florestas amedrontantes de dor, com trilhas desconhecidas; em tal contexto, ouvir histórias, para aqueles que sofrem, pode significar novos caminhos para sair da escuridão ${ }^{7}$.

Os contos orais vieram antes dos textos escritos em todas as tradições religiosas. Há muito é reconhecido na espiritualidade judeo-cristã, por exemplo, que os próprios textos sagrados originaram-se de histórias orais que traziam não apenas proezas, mas também os ensinamentos tradicionais ${ }^{8}$, uma vez que as narrativas maiores (o Pentateuco ou as histórias deuteronômicas, isto é, aquelas dos cinco primeiros livros do Antigo Testamento atribuídos a Moisés: Gênesis, Êxodo, Levítico, Números e Deuteronômio) careciam da estrutura enxuta das histórias orais do dia-a-dia, a partir da qual esses épicos foram compostos. Um histórico maior sobre as tradições orais e escritas, e o efeito da ausência de aptidão literária geral, é fornecido por Nidith ${ }^{9}$.

Para iniciar a discussão, serão esclarecidos três termos: espiritualidade, fé e religião.

O termo espiritualidade tem diversos significados, muitas vezes utilizados erroneamente, como sinônimos de religião ou, pejorativamente, como sinônimos de religiões não-tradicionais e não-institucionalizadas (experiências da Nova Era, por exemplo). Aqui, utilizaremos várias definições úteis de praticantes externos às organizações religiosas. Canda ${ }^{10}$ define espiritualidade como a "busca humana pelo significado pessoal e pelos relacionamentos mutuamente recompensadores entre pessoas, o ambiente não-humano e, para alguns, Deus”. Já Bullis ${ }^{11}$ a conceitualiza como "os sentimentos e experiências internas de proximidade com 
um poder superior [...] como o relacionamento da pessoa humana com algo ou alguém que a transcende", sugerindo que a espiritualidade é um estado de consciência focado divinamente, mas alterado. Ao discutir a necessidade essencial de aplicar a espiritualidade a um trabalho social compassivo, Angell, Dennis e Dumain ${ }^{12}$ argumentam que esta se resume em "uma busca ou necessidade intrínseca da humanidade”, e é tecida na resposta da pessoa à sua própria percepção de Deus. A espiritualidade é concebida aqui, de modo amplo, como uma busca dinâmica e contínua no íntimo das pessoas pelo significado de sua relação particular com um poder divino superior.

Como a fé é o tema central das histórias contadas nas tradições espirituais, torna-se útil analisar seu significado geral. Dentro da tradição judeo-cristã, a Carta aos Hebreus declara que fé é ter certeza daquilo que esperamos e daquilo que não vemos $(11,1)$. As pessoas passam a acreditar na provável ocorrência ou existência de eventos ${ }^{13}$.

Dos três termos, religião parece ser o mais fácil de definir, pois, de modo geral, aceita-se que ela se manifesta em uma associação daqueles que compartilham valores e crenças. Há uma argumentação geral, tanto dentro quanto fora de certas entidades religiosas, de que religião é um grupo de fiéis que, dentro de uma organização ou instituição, aceita um conjunto comum de crenças, práticas e rituais relacionados aos interesses espirituais e às questões éticas ${ }^{14}$. Como resultado, a espiritualidade constitui uma prática e um sistema de crença menos doutrinais, ritualizados e, talvez, menos tangíveis. Aqui, uma interseção é oferecida para enquadrar a discussão acerca de histórias; dá-se atenção ao uso de relatos orais com vistas a gerar a fé nas instituições religiosas. Minha posição é a de que as pessoas precisam de espiritualidade para dar sentido ao mundo, guiar suas escolhas sobre o que crer ou rejeitar, determinar o que valorizar e sinalizar opções comportamentais. As religiões oferecem estrutura, apoio e alicerces específicos para a necessidade espiritual. Storytelling é uma ferramenta vital para satisfazer essas necessidades e metas.

Histórias orais, de fato, podem ser um recurso ímpar para alimentar o espírito, pois produzem impacto emocional. Um conto poderoso é sempre fundamentado, não na trama, mas na emoção, que a oralidade da narrativa destaca. A emoção, por sua vez, é o local exclusivo de morada da alma. O modo pelo qual a emoção de um conto é comunicada, porém, torna-se mais difícil de compreender.

A investigação da trama emocional de uma história envolve prestar atenção à sua essência. Harold Scheub, professor de humanidades e de língua e literatura africana "Evje-Bacom" da Universidade de Wisconsin, em Madison, colecionou contos orais ao caminhar mais de seis mil milhas ${ }^{15}$ pela África do Sul, Suazilândia, Zimbábue e Lesoto. Ele era motivado pela pergunta: "Qual a essência da história?”. Como o contador de histórias transmite significado? Aprendeu isso por meio de Nongenile Masithathu Zenani, uma mulher que, dentre esses contadores de histórias, admitiu que freqüentemente se via em uma batalha entre a tradição e as tendências sociais contemporâneas. Ela ex-
(Espiritualidade, diversidade religiosa e prática de assistência social). Social Casework, 69(4), 238-247 1988.

11. BULLIS, R. K. Spirituality in social work practice (Espiritualidade em prática de assistência social). Washington, DC: Taylor \& Francis, 1996.

12. ANGELL, G. B.; DENNIS, B. G.; DUMAIN, L. E. Spirituality, resilience, and narrative: coping with parental death (Espiritualidade, resiliência e narrativa: lidando com morte parental). Families in Society, 79, 615-630, 1998 .

13. Ibid.

14. Ibid. KRIPPNER S.: WELSH, P. Spiritual dimensions of healing (Dimensões espirituais da cura). New York: Irvington Publishers, 1996.

15. Equivalente a $9.655,8$ quilômetros. 
plicou como entendia a parte mais profunda da "história": "Contar histórias é uma junção sensorial de imagens e idéias, um processo de recriar o passado nos termos do presente" 16 .

\title{
ESTRUTURAS DE HISTÓRIAS
}

\begin{abstract}
História
1. uma narrativa, seja verdadeira ou fictícia. 2. um jeito de saber e lembrar informações; uma forma ou padrão no qual informações podem ser organizadas e experiências, preservadas. 3. uma ordem antiga e natural da mente. 4. fragmentos isolados e desconexos da experiência humana ligados em um todo significativo.
\end{abstract}

Embora a "definição" acima de história seja, de fato, minha própria mescla de várias perspectivas úteis, ela nos convida a atentar para as estruturas das histórias. Ainda que acadêmicos tenham prestado atenção limitada às suas estruturas dentro das tradições espirituais, algumas descobertas apareceram. Quando se pergunta ao padre Brian Cavanaugh onde ele encontra todas suas histórias, ele sempre responde com simplicidade "Como é que você não as percebe?"17. Contos, para aqueles que os contam, estão em todos os lugares, em diversas formas.

Homilias, isto é, pregações em estilo familiar feitas na tradição cristã, geralmente incluem relatos recontados a partir do Antigo ou Novo Testamentos; narrativas autobiográficas sobre sua própria conversão, compromissos ou sobre seus ministérios; e histórias de outros integrantes da congregação. Nossa distinção inicial entre espiritualidade e religião é útil aqui, pois os contadores de histórias há muito reconhecem que não é necessário compartilhar de uma religião para que uma pessoa seja profundamente tocada por seus contos: "Não me considero uma pessoa muito religiosa, mas o Antigo Testamento realmente me atrai - bem mais do que o Novo - e sempre me pareceu que aqueles meus amigos alemães de minha infância haviam saído diretamente do Antigo Testamento. O campo, os rebanhos, a vida patriarcal, as viagens lentas, a fé simples das pessoas e a influência da Bíblia em seu cotidiano, tudo isso teve um forte impacto sobre mim e essa impressão nunca se apagou" ${ }^{18}$.

Essas histórias têm um apelo muito grande em virtude de seus temas e personagens. Os temas são bastante abrangentes e incluem arrependimento, perdão, ressurreição e necessidade de justiça social ${ }^{19}$. Além disso, as próprias estruturas das histórias envolvem aspectos temáticos (isto é, o certo e o errado, o sofrimento, a amizade com Deus e com os outros, a imortalidade e o papel da Igreja). Dentro das tradições judeo-cristãs, até mesmo histórias familiares são contadas denominacionalmente, ou seja, de modo diferente (um rabino contará uma história sobre Moisés, Deus, ou sobre a sarça ardente de maneira diversa de um bispo anglicano, por exemplo). A repetição do tema cria uma 
estrutura que tem poder de persuasão.

As idéias ou conjuntos de imagens lingüísticas recorrentes nos contos contrastam com os temas. Em vez de enfatizar um ponto moral, as idéias são padrões significativos de imagens que elevam o apelo narrativo, misturando-se de tal forma que as imagens se sucedem até que, enfim, elas conduzem o ouvinte ao significado da história. O mesmo pode ocorrer com os personagens.

A distinção judaica entre "halakah" e "haggadah" ajuda a jogar luz no formato distinto de história. Halakah é uma reflexão ponderada sobre a lei religiosa, de natureza abstrata. Já haggadah é "o caminho da metáfora e das figuras" ${ }^{20}$. Faça uma pergunta a um rabino, e você ouvirá uma história. Os evangelhos, da Bíblia, são de natureza "hagádica".

O linguajar utilizado no storytelling dentro de contextos religiosos geralmente deriva da linguagem coloquial, ou das palavras que as pessoas empregam em sua vida diária. Os contadores de histórias freqüentemente falam "eu" ou "nós" para dar sentido ao conto e aproximá-lo das pessoas. Eles salpicam palavras vívidas em toda a narrativa a fim de retratar detalhes cênicos. Schuetz ${ }^{21}$ descreve como fazer sermões envolve dramatização e interpretação de papéis na tentativa de persuadir a audiência tanto pelo conteúdo quanto pelo estilo. Nas histórias, ambos os aspectos verbais e não-verbais da comunicação estão presentes e são utilizados.

As fábulas são narrativas curtas que dependem quase exclusivamente do uso de animais como personagens. Como resultado, focam nossa atenção no comportamento e nos dilemas universais da vida em vez de em determinadas pessoas. Revisadas e adotadas pela cultura que foi exposta a elas, as fábulas apareceram amplamente na literatura, em geral com um imperativo moral explícita ou implicitamente revelado no final do conto. Embora não gostasse de moralizações, Martin Luther King ${ }^{22}$ as empregou em seus sermões e ensinamentos, pois pensava que elas continham sabedoria em um formato conciso e simples. Certa vez escreveu: "Depois da Bíblia, os escritos de Cato e de Esopo são os melhores; melhores do que todas as opiniões dos filósofos e juristas" ${ }^{23}$. Como um conto de sabedoria, a fábula relaciona-se ao provérbio, embora possa ter uma trama maior; alguns se referem a ela como provérbios estendidos. Uma fábula, por exemplo, mostra como pessoas vãs e gananciosas acabam sofrendo as conseqüências de suas escolhas tolas; demonstra também que crianças que mentem freqüentemente acabam sendo ignoradas e devoradas.

Já as parábolas, outra forma de estrutura de histórias, vêm sendo usadas como recurso popular a fim de contar histórias espirituais. William Bausch ${ }^{24}$, um padre da diocese de Treton, Nova Jérsei, é um defensor do uso do storytelling pelos pregadores em todo o mundo. Ele enfatiza que as parábolas contêm sabedoria, e cita Mateus 13,34: "Jesus disse às multidões todas essas coisas em parábolas; sem uma parábola, ele nada dizia a elas”.

Bausch situa o dilema do contar histórias e da espiritualidade bem no âmago dos efeitos de mídia, citando a preocupação de George Gebner, do
20. WHITE, W. R. Stories for telling: a treasury for Christian storytellers (Histórias por contar: um tesouro para contadores de histórias cristãos). Minneapolis, MN: Augsburg Publishing House, 1986. p. 17.

21. SCHUETZ, J. Oscar Romero: archbishop of "the people" (Oscar Romero: arcebispo do povo). Religious Communication Today, 7, 19-26, 1984.

22. Martin Luther King (Junior) foi pastor evangélico e ativista política americano. Nasceu em Atlanta, em 15 de janeiro de 1929 Pertencente à Igreja $\mathrm{Ba}$ tista, tornou-se um dos mais importantes líderes ativistas pelos direitos cívicos e do movimento negro nos Estados Unidos e no mundo, através de uma campanha de nãoviolência e de amor para com o próximo. Recebeu - Prêmio Nobel da Paz em 1964. Foi assassinado em Memphis, Alabama, em 4 de abril de 1968, por um homem branco. Disponivel em: <http:// pt.wikipedia.org/wiki/Martin_Luther_King>, acesso em 16 de julho de 2005, às $18 \mathrm{~h} 43$.

23. WHITE, W. R. Stories for telling..., op. cit., p. 21.

24. BAUSCH, W. J. A world of stories for preachers and teachers (Um mundo de histórias para 
Centro Annenberg para Estudos de Mídia na Universidade da Pensilvânia, o qual observou que, pela primeira vez na história, os principais contos que as crianças aprendem não vêm de seus familiares, mas das empresas globais de mídia com fins lucrativos ${ }^{25}$. Buscando corrigir esse desequilíbrio, Bausch colecionou mais de 350 contos, para pregadores e professores, destinados a "julgar, provocar e estimular a imaginação espiritual"; a seleção deles dependeu, em parte, da estrutura de suas narrativas (curtas, mas profundas). Nada da recente proliferação de histórias "bonitinhas", já que Bausch argumenta que estas perpetuam a superficialidade da mídia ("bolinhos literários, cheios de açúcar mas pouco nutritivos") ${ }^{26}$.

William White ${ }^{27}$, um pastor luterano de Michigan, elaborou um guia para o uso de histórias em igrejas. Ele apontava há algumas décadas que a revolução da comunicação trazida pelo advento da televisão, alteraria dramaticamente as expectativas dos fiéis para com seus pregadores. Chega de leituras no púlpito; as pessoas nos bancos da igreja agora esperam contato visual, bem como intelectual, em uma linguagem vívida, concreta e clara. Além disso, a televisão, aberta ou a cabo, agora dá mais opções espirituais às pessoas: o pastor em casa, o padre à disposição, ou um dos muitos rostos sorridentes (com a orquestra completa e um coral vestido a caráter) no aparelho de televisão, todos os domingos pela manhã - batalhas de histórias, de certo modo, pois a televisão é um meio que conta histórias. White argumenta que a televisão transformou a leitura de um sermão de uma pequena infração em um crime doloso. Os novos meios podem nos forçar a prestar ainda mais atenção, mas o storytelling sempre foi tanto um instrumento de fé quanto uma poderosa ferramenta de comunicação.

\section{EFEITOS DE OUVIR HISTÓRIAS}

Houve uma vez um mercador cuja mulher estava doente e, então, quando ela sentiu a morte se aproximar, pediu à única filha que se aproximasse de seu leito. Urgentemente, com uma voz cheia de amor, ela disse a sua filha, "Seja devota e boa, e Deus sempre cuidará de você. E para sempre olharei para você do céu, e assim você nunca ficará sem mim”. Então, fechou os olhos e morreu. A filha visitava o túmulo de sua mãe todos os dias e chorava amargamente.

pastores e professores). Mystic, CT: Twenty-Third Publications, 1999.

25. Ibid., p. 1.

26. Ibid., p. 2.

27. WHITE, W. R. Stories for telling..., op. cit., p. 15.
AschenPUtTEL

(Uma versão antiga de um conto do tipo Cinderela, adaptada pelo autor a partir de muitas fontes. Originalmente, um conto folclórico coletado na Alemanha por Jacob e Wilhelm Grimm, os irmãos Grimm.)

As palavras mágicas "Era uma vez...", que muitas vezes iniciam um conto folclórico ou de fadas tradicional, induzem um transe relaxante, familiar e 
leve. De fato, comumente diz-se que se "mantém uma audiência enfeitiçada" ao descrever o estado em que as pessoas ficam quando ouvem um relato bem contado e psicólogos já afirmaram que performances de contadores de histórias contêm muitas das condições necessárias para induzir transes ${ }^{28}$. Um psicoterapeuta, também contador de histórias, descreveu tais transes como um estado de consciência voltado para dentro da pessoa, de tal forma que os olhos dos ouvintes podem estar no contador de histórias, porém suas consciências estão voltadas para dentro delas mesmas ${ }^{29}$. Benson ${ }^{30}$ descreve a Resposta Relaxante, relacionando dados médicos ocidentais com práticas religiosas orientais. Quando os ouvintes encontram-se relaxados, estão abertos para uma retenção mais ativa daquilo que está sendo dito, ficam menos defensivos e os processos internos de seus próprios corpos maravilhosos começam a "curar" (a pressão arterial cai, as dores diminuem, a respiração torna-se levemente rítmica, os batimentos cardíacos diminuem e encerra-se a produção dos hormônios do estresse). O "transe de ouvir histórias" foi identificado pela primeira vez por Stallings ${ }^{31}$, que tinha interesse na biofisiologia de adultos durante a narração de histórias.

O efeito do transe foi estudado posteriormente por Sturm ${ }^{32}$. Adultos ouvintes muitas vezes reconheciam ter percepção de seus próprios estados profundamente alterados de consciência e até mesmo uma sensação de experimentar a história de ficção como realidade, identificando-se com os personagens, tramas ou papéis ("Não estava mais sentado em uma tenda ouvindo alguém contar uma história. Eu estava naquela mata, vi aqueles animais") ${ }^{33}$.

Contos folclóricos e de fadas são acompanhados por "induções" familiares para dar boas-vindas ao transe curador:

\section{Era uma noite escura e chuvosa..}

Era uma vez, em uma terra muito distante...

Na época em que a mágica ainda existia, havia um rei...

Era uma vez...

O conto falado, em si, dá continuidade ao transe, e não apenas reproduz o conto literário: repetições, ritmos de voz, silêncios, sussurros, todos conduzem a um relaxamento ainda mais profundo.

Rooks $^{34}$ argumenta que, quando nosso mundo está cheio de pesar e dor, enxergar a nós mesmos claramente é impossível, já que um nevoeiro cerca nossas mentes. Como as histórias têm a habilidade de nos surpreender, elas penetram em nossa alma, sem a necessidade de aceitação ou consciência imediata. Entretanto, Rooks destaca o efeito de ouvir uma história quando estamos sofrendo: a história não nos julga. Uma boa narrativa é aquela que podemos aceitar ou rejeitar e, paradoxalmente, tal liberdade torna mais provável a aceitação. Daniel Taylor, um professor de inglês de Bethel College, em Minnesota, escreve que as pessoas hoje estão confusas sobre quem são, por que estão aqui e o que devem fazer — dúvidas que tradicionalmente foram mais bem respondidas por
28. SUNWOLF, J. D.; FREY, L R.; KERÄNEN, L. R. Story-prescriptions: healing effects of storytelling and storylistening in the practice of medicine (Efeitos curativos da narração e audição de histórias na prática de medicina). In: HARTER, L. M.; JAPP, P. M.; BECK, C. S. (Eds.). Constructing our health: the implications of narrative for enacting illness and wellness (As implicações das narrativas por contar e falar de doenças). Mahwah, NJ: Lawrence Erlbaum. No prelo.

29. MARTIN, S. Altered states (Estados alterados). Storytelling Magazine, 5, 20-23, 1993

30. BENSON, H. The relaxation response (A resposta de relaxamento). New York: Avon, 1975.

31. STALLINGS, F. The web of silence: the story listening trance (A teia de silêncio: o transe de ouvir histórias). National Storytelling Journal, 5,6-19, 1988.

32. STURM, B. W. The "storylistening" trance experience (A experiência do transe ao ouvir história). Journal of American Folklore, 113, 287-304, 2000.

33. Ibid., p. 290.

34. ROOKS, D. Spinning gold out of straw: how stories heal (Separando ouro de palha: como histórias curam). St. Augustine, FL: Salt Run Press, 2001. 
35. TAYLOR, D. The healing power of stories: creating yourself through the stories of your life $(\mathrm{O}$ poder curativo de histórias: criando pelas histórias de sua vida). New York: Doubleday, 1996.

36. TAYLOR, S. E. et al. Storytelling and coping with stressful events (Contando histórias e lidando com eventos estressantes). Journal of Applied Social Pychology, 23, 703-733, 1993.

37. Ibid.

38. WHITE, W. R. Stories for telling..., op. cit., p. 16. histórias $^{35}$. Em um sentido muito real, Taylor argumenta que o ato de contar histórias ajuda as pessoas a perceber que são personagens de uma história maior e que elas a compartilham com um mundo de outros personagens. Ajudá-las a notar seus papéis em uma história mais ampla tira-as do foco estreito em si mesmas, estimulando-as gentilmente a se concentrar em suas comunidades e nas histórias tecidas e compartilhadas que as cercam.

Não apenas o contar histórias, mas também ouvi-las parece ter importantes efeitos, documentados por acadêmicos interessados nos resultados comunicativos do storytelling. Taylor, Aspinwall, Giuliano, Dakof e Reardon ${ }^{36}$ conduziram três estudos para explorar os benefícios e as limitações das histórias de superação. Curiosamente, pacientes de câncer reportaram que narrações positivas sobre outros pacientes ajudavam mais do que as negativas, ainda que fosse mais comum as pessoas contarem-lhes as negativas (dois terços eram sobre pacientes que haviam morrido ou reagido mal ao câncer). A origem de um relato pode influenciar a maneira pela qual o ouvinte o entende. Taylor e seus colegas postularam que as histórias mais efetivas podem derivar de outras semelhantes ou de especialistas. Quando os pesquisadores manipularam a valência (positivo ou negativo) e a origem das histórias contadas a estudantes de faculdades prestes a fazer suas provas bimestrais, aquelas com finais positivos e as contadas por especialistas foram consideradas de forma mais satisfatória do que as negativas e aquelas contadas por não-especialistas ${ }^{37}$. No terceiro estudo, três grupos de estudantes ouviram histórias sobre como outros colegas se ajustaram mal à faculdade, sobre níveis médios de ajuste, ou de grande sucesso; havia duas outras condições: de histórias informativas, contendo dados relevantes de como se poderia melhorar o ajuste à vida na faculdade, ou de história não-informativa. As histórias negativas fizeram os alunos sentirem-se com sorte em comparação a outros, enquanto as positivas foram entendidas como se oferecessem um modelo melhor e uma sensação de esperança.

Isso sugere que contar histórias dentro de comunidades espirituais pode ter efeitos poderosos para ajudar seus membros a lidarem com eventos dolorosos e desafios. "A história evoca uma resposta mais poderosa de fé do que doutrinas e conceitos." ${ }^{8}$

\section{$R_{\mathrm{X}}$ : REMÉDIO PARA A ALMA, PÍLULAS ESPIRITUAIS}

Há muito, muito tempo atrás, um homem conhecido como Baal Shem Tov foi ao lugar mais secreto da floresta. Conta-se que, nesse local secreto, ele acendeu uma fogueira sagrada, recitou uma prece antiga e pronunciou um nome sagrado. Naquele momento, a Esperança ficou mais forte no mundo. Mas acontece que, na geração seguinte, seu sucessor sabia apenas onde ficava o lugar, como acender a fogueira e conhecia a prece. Ainda assim, isso era suficiente para preservar a Esperança. Cada geração dali por diante perdeu mais uma das fagulhas do conhecimento 
até que, por fim, nada sobrou, exceto a história. Mas contar a história ainda era suficiente.

Doug Lipman ${ }^{39}$, adaptado de um conto oral

Quando a esperança é o remédio de que se precisa para um espírito ferido, histórias são a receita certa. Um método prescritivo de contá-las ilumina o poder de narrar "cara a cara" para alimentar ou curar as mentes e as almas de várias maneiras. Contar e ouvir histórias no contexto das tradições espirituais pode agir de diversas maneiras dinâmicas. Um modelo funcional de histórias é oferecido na Figura 1, que sugere que os contos narrados e ouvidos dentro de vários contextos espirituais podem funcionar como (a) uma maneira de conectar diferentes pessoas (narrativas relacionais), (b) um modo de aprender (narrativas pedagógicas), (c) uma forma de criar (narrativas heurísticas), ou (d) um jeito de lembrar (narrativas históricas), ou (e) um meio de visualizar o futuro (narrativas visionárias). Esse modelo convida-nos a reconhecer ainda mais a natureza permeável dessas categorias, já que qualquer história contada pode prover várias funções sobrepostas a um ou mais ouvintes ou contadores. Um método comunicativo funcional para pensar sobre o papel do contar histórias em relacionamentos foi sugerido pela primeira vez por Sunwolf e Frey ${ }^{40}$. Estes descreveram como o modo interpessoal de contar histórias, "cara a cara", ajuda os contadores e suas audiências a construir o próprio "eu" (Quem sou eu?); a tecer a comunidade (Quem somos nós?); a ordenar experiências; a representar a realidade; a achar o sentido de eventos vividos; a compartilhar o conhecimento; ou a influenciar valores, crenças e ações uns dos outros.

Este artigo utilizará as categorias desse modelo de história funcional como um sistema para apresentar o conhecimento que examina os efeitos da narrativa oral, incluindo o conhecimento da perspectiva de várias tradições espirituais.

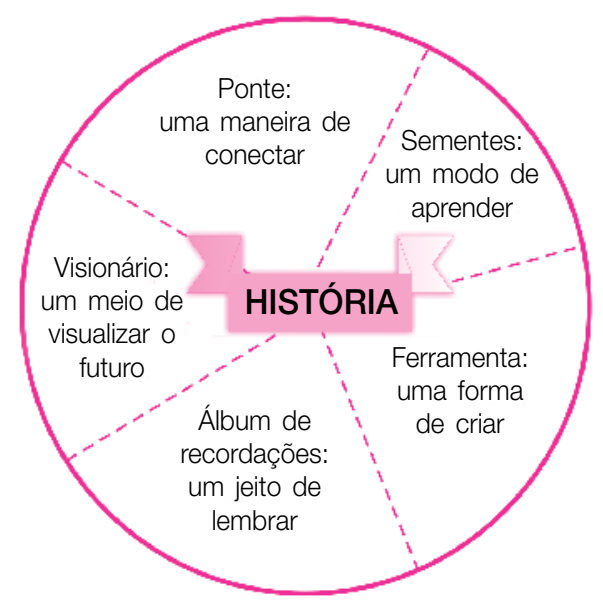

Figura 1. Modelo de cinco funções de histórias orais para contadores e ouvintes.

Nota: As linhas pontilhadas entre os tipos de história simbolizam a natureza permeável de cada tipo (misturando um com o outro e cruzando os limites). Modelo expandido e adaptado de Sunwolf, Frey e Karänen (no prelo).
39. LIPMAN, D. The soul of hope: an oral performance (A esperança da alma: um desempenho oral). Schenectedy, New York, 1996. Comunicação pessoal.

40. SUNWOLF, J. D.; FREY, L. R. Storytelling: the power of narrative communication and interpretation (Contar histórias: poder de comunicação narrativa e interpretação). In: ROBINSON, W. P.; GILES, H. (Eds.). The new handbook of language and social psychology (O novo manual de linguagem e psicologia social). London: Wiley, 2001. p. 119-135. 


\section{Ponte de histórias: uma maneira de conectar}

Assim como uma ponte, uma história representa um paradoxo valioso. Qualquer conto pode unir ou separar as pessoas. As histórias têm a capacidade paradoxal de ferir e curar. Todos nós sentimos, em nossas vidas pessoais e profissionais, o impacto das narrativas que ferem: fofocas, difamação ou rumores distorcidos causam efeitos devastadores na saúde emocional e física das vítimas do lado escuro do "contar histórias". Na tradição judaica, os antigos rabinos cunharam um termo para descrever o poder das histórias negativas, "lashon hara", que significa "falar com uma língua má". Limites foram impostos no sentido de quais histórias poderiam ser repetidas, pois se pensava que o próprio ato de contá-las daria peso às suas palavras ${ }^{41}$. Esse poder danificador é contrabalançado com o poder de cura de algumas delas. Meade ${ }^{42}$, terapeuta que treina outros terapeutas no uso de histórias de cura, acredita que novos significados são criados cada vez que uma história é contada, tanto para os ouvintes quanto para os contadores.

As pessoas sempre contam histórias sobre si mesmas, fazendo poderosas

41. STONE, R. The healing art of storytelling: a sacred journey of personal discovery (A arte curativa da narração: uma viagem sagrada da descoberta pessoal). New York: Hyperion, 1996

42. MEADE, E. H. Tell it by heart: women and the healing power of a story (Fale de cor: as mulheres e o poder curativo de uma história). Chicago: Open Court, 1995.

43. WITHRELL, C. S.; TRAN, H. T.; OTHUS, J. Narrative landscapes and the moral imagination: taking the story to heart (Paisagens narrativas e a imaginação moral: levando a história ao coração) In: McEWAN, H.; EGAN, K. (Eds.). Narrative in teaching, learning, and research (Ensino, aprendizagem e pesquisa com narrativa). New York: Teachers College Press, 1995. p. $39-49$

44. SCHEIBE, K. E. Selfnarratives and adventure (Auto-narrativas e aventura). In: SARBIN, T. R. (Ed.). Narrative psychology: the storied nature of human conduct (Psicologia narrativa: a natureza da conduta humana contada). New York: Praeger, 1986 pontes de partilha com os outros. Witherell, Tran e Othus ${ }^{43}$ sugerem que a narração oral permite que a audiência se engaje em um surto de empatia que a liga a relacionamentos mais amplos, os quais constroem pontes que atravessam as culturas. Scheibe ${ }^{44}$ descobriu que, para algumas pessoas, as histórias que construíram para suas vidas (e que compartilham com outros) de fato parecem terminar antes de suas vidas biológicas. Aqueles que não conseguem enxergar mais "história" em suas vidas deixam de viver por completo.

\section{Sementes de histórias: um modo de aprender}

Era uma vez uma criança que ganhou um presente diferente. Bagdá inteira comemorou o nascimento do filho do sultão e presentes caros foram comprados por todos os nobres, sacerdotes e sábios. Um jovem sábio foi convidado para ir às comemorações, mas foi de mãos vazias. Ele curvou-se diante do sultão, falando em baixo tom: "Hoje o jovem príncipe recebeu muitos tesouros preciosos, caros além da imaginação. Aqui está meu humilde presente: no momento em que ele tiver idade suficiente para ouvir, e até que se torne adulto, virei ao palácio todos os dias e contarei histórias para ele”. O jovem sábio manteve sua palavra e um dia o príncipe tornou-se sultão. Ele ficou famoso por sua sabedoria. Até hoje, uma inscrição em um pergaminho em Bagdá diz apenas: Foi por causa da semente plantada pelos contos.

As histórias respondem tanto às perguntas "por que?" quanto às "por que não?”, permitindo que os ouvintes aprendam através delas. Os estudos sobre os processos mediante os quais o contar histórias facilita o aprendizado lançam luz, já no início, em como seu uso dentro das tradições religiosas é, freqüente- 
mente, o de pedagogia. Livo e Rietz ${ }^{45}$ argumentam que na narrativa oral nos é apresentada uma verdade sobre quem somos e mesmo sobre por que somos quem somos, pois o conto apropria-se do comum e associa-o à existência humana, revelando a importância do trivial. De fato, estudiosos há muito concordam que sistemas de histórias ajudam-nos a organizar as experiências e a aprender a partir delas; Polkinghorne ${ }^{46}$ argumenta que uma história torna um evento individual compreensível ao identificar o todo com o qual um único evento contribui. Como este é um dos principais objetivos das religiões organizadas (Por que coisas ruins acontecem com pessoas boas?), histórias são valiosas para ajudar as pessoas a aprenderem a partir dos acontecimentos em suas vidas.

Wanner ${ }^{47}$ descobriu que o processo de compartilhar narrativas orais valoriza uma determinada lógica do saber: enquanto a linguagem escrita pode apresentar lógica dedutiva ou indutiva, a linguagem falada apresenta uma visão mais dinâmica. Por exemplo, a análise lingüística de Gee ${ }^{48}$ sobre o tempo de partilha de histórias de uma criança afro-americana de sete anos, na fase escolar de "mostrar e contar", é evidência de que ela pode compreender suas experiências através de um estilo oral de fala que difere do estilo culto do professor.

Muitas tradições religiosas utilizam "ensinar histórias" para influenciar escolhas morais. Os judeus chassídicos* utilizavam a história como principal meio para instruir suas crianças a elucidarem o significado do Antigo Testamento ${ }^{49}$. Narrativas apareceram em muitas formas nos primeiros sermões e na literatura devocional cristã, falando sobre as vidas de santos, modelos da vida religiosa correta, fábulas, das quais os pregadores retiravam elementos de moralidade e até ilustrações para rememorar, oralmente, a vida de Jesus ${ }^{50}$. Storytelling é um modo de persuasão religiosa que floresceu na Idade Média e foi a ferramenta básica dos evangelistas nos Estados Unidos, no século XX.

Kaufman $^{51}$ oferece uma descrição antropológica completa da literatura de "sabedoria", inclusive das fábulas, apólogos, parábolas, contos religiosos, anedotas, contos de moral, piadas e provérbios. Todos esses tipos de histórias derivam de um gênero que continha um propósito comunicacional duplo (conhecido no espanhol como instruir deleitando, ou seja entreter, mas, ao mesmo tempo, ensinar). As histórias têm o poder de ensinar moralidade, evitando o formato de palestra, que é desagradável para os ouvintes. O arcebispo dom Oscar Romero foi influente, em parte, por causa de sua habilidade em escrever histórias nas quais personagens maus perdiam a luta contra os bons ${ }^{52}$. Anteriormente, argumentei que os efeitos persuasivos de histórias orais ao transportar aprendizados profundos para os ouvintes podem derivar de $(a)$ pensamentos autogerados pelo ouvinte enquanto escuta o conto, $(b)$ da percepção cognitiva ativa do ouvinte durante a narrativa do conto, $(c)$ da modelagem de comportamentos e valores apropriados (ou caros) na trama do conto e/ou $(d)$ da introdução de eventos ou conseqüências que provocam deliberação consciente ${ }^{53}$.

O papel do storytelling na tradição espiritual de muitos povos nativos norteamericanos incluía a crença de que uma história bem contada seria lembrada
45. LIVO, N.; RIETZ, S. Storytelling: process and practice (Contar histórias: processo e prática). Littleton, CO: Libraries Unlimited, 1986.

46. POLKINGHORNE, D. E. Narrative knowing and the human sciences (Narrativa do conhecimento e as ciências humanas). Albany, NY: State University of New York Press, 1988.

47. WANNER, S. Y. On with the story: adolescents learning through narrative (Com a história: adolescentes que aprendem através da narrativa). Portsmouth, $\mathrm{NH}$ : Boynton/Cook, 1994.

48. GEE, J. P. The narrativization of experience in the oral style (A narrativização de experiência no estilo oral). Journal of Education, 167, 9-35, 1985.

* Relativos à corrente mística moderna, inspirada na Cabala. (N.E.)

49. MINTZ, J. R. The legends of Hasidism: an introduction to Hasidic culture and oral tradition in the New World (As lendas de Chassidismo: uma introdução para cultura chassídica e tradição oral no Novo Mundo). Chicago: University of Chicago Press, 1968.

50. SCHUETZ, J. Oscar Romero: archbishop of..., op. cit. GERHARDSON, B. Memory and manuscript: oral tradition and written transmission in rabbinic Judaism and early Christianity (Memória e manuscrito: tradição oral e transmissão escrita no Judaísmo rabínico e no cristianismo primitivo). Trad. E. J. Sharpe. Copenhagen: Ejnar Munksgaard, 1961.

51. KAUFMANN, W. O The anthropology of wisdom literature ( $A$ antropologia da literatura da sabedoria). Westport, CT: Bergin \& Garvey, 1996.

52. SCHUETZ, J. Oscar Romero: archbishop of..., op. cit. Id. Storytelling and preaching: a case..., op. cit.

53. SUNWOLF, J. D. The pedagogical and persuasive effects..., op. cit. 
54. BRUCHAC, J. Roots of survival: native american storytelling and the sacred (Raízes da sobrevivência: narração americana nativa e o sagrado). Golden, $\mathrm{CO}$ : Fulcrum, 1996.

55. FRIEDLANDER, S. Talks on Sufism: When you hear hoofbeats think of a zebra (Conversas em Sufi: quando ouvir um tropel, pense em uma zebra). Costa Mesa, CA: Mazda, 1992.

56. BASCOM, W. R. African dilemma tales (Contos de dilema africanos). Paris: Mouton, 1975

57. MILLER, A L. Spiritual accomplishment by misdirection: some Upâya folktales from East Asia (Realização espiritual através de instruções erradas: alguns contos folclóricos de Upâya da Ásia Oriental). History of Religions, 40, 82-108, 2000.

58. FREY, R. The world of the Crow Indians: as driftwood lodges $(\mathrm{O}$ mundo dos índios Corvo: como chalés de madeira flutuante). Norman: University of Oklahoma Press, 1987. por mais tempo pela audiência do que dizer "você deve!" ou "você não deve!" Os contos da sabedoria sufista, originários do Oriente Médio, reconhecem o poder das histórias orais para enfatizar pontos de ensinamento sem ordenar a resistência mental que o raciocínio lógico mais afiado aparenta deflagrar ${ }^{55}$. Já contos de dilemas africanos trazem ensinamentos morais profundos, muitas vezes negociados e renegociados dentro das próprias comunidades que os contam. Tais contos funcionam como uma parte integral do treinamento moral e ético em muitas sociedades africanas; eles terminam com uma pergunta, que deve ser respondida pelos ouvintes ${ }^{56}$.

Os contos folclóricos dos Upâya, do leste asiático, propõem ensinamentos espirituais através da técnica de "instruções erradas". Miller ${ }^{57}$ conclui que há uma conexão intricada entre as estratégias narrativas dos contadores de histórias e as mensagens religiosas e morais. A estrutura desses contos folclóricos fundamenta-se em um ser super-humano central que aparece para trazer melhorias espirituais ou morais a alguém. Há, portanto, uma intervenção sobrenatural nos assuntos humanos. Os contos são baseados em sabedoria transcendental (prajñâ), isto é, o conhecimento claro da realidade, como ela verdadeiramente é, que deve incluir a introspecção para o estado espiritual da pessoa na qual o poder sobrenatural deve operar. As ações são conduzidas pela compaixão, com o intuito de ajudar outras pessoas e que vem diretamente de sentir o sofrimento delas como se sente o próprio pesar, de forma que as deidades são altamente empáticas. Um exemplo do poder de ensinamento desses contos folclóricos é a famosa parábola da "Casa em Chamas", recontada por Miller, e resumida aqui:

O personagem central é um pai benevolente, que tem muitos filhos. O pai volta para casa e descobre que ela está em chamas; mas, seus muitos filhos estão tão envolvidos com brincadeiras que ignoram seus gritos para que saiam da casa. Assim, decide contar uma mentira. Ele diz que trouxe vários brinquedos novos para eles brincarem, e que estão lá fora. Ouvindo isso, todas as crianças correm para fora, mas não há brinquedos novos.

Nessa tradição de instruções erradas, insiste-se que não há, na verdade, nenhuma "mentira". O que ocorre é que se trabalha com uma sabedoria transcendental misteriosa.

\section{Ferramentas de histórias: uma forma de criar}

Histórias podem funcionar como receitas para o pensamento futuro sobre comportamentos e resultados. Em comunidades religiosas, a justiça social e a mudança são os principais objetivos, além da busca pela iluminação pessoal. Frey $^{58}$, estudando contos orais de tradições espirituais dos nativos americanos, argumenta que as próprias "palavras" às vezes são produtivas. Muitas tradições espirituais acreditam que narrar um conto tem o poder de trazer o evento ao presente. Assim, os contos são perigosos e sagrados. Em especial, alguns povos 
nativos americanos consideram suas histórias como ferramentas de comunicação que funcionam ao "representar" acontecimentos poderosos, bem como ao criar eventos novos ${ }^{59}$. Bruchac ${ }^{60}$ descreve a forma pela qual os povos nativos da região sudeste disseram que contar histórias sobre coiotes, por exemplo, na época errada do ano, é um convite para que o pregador de peças (o coiote) venha visitar o contador - trazendo sempre problemas indesejados. Nossas crenças religiosas são guias vivos, sempre iluminando o caminho na direção da possibilidade de um tempo melhor no futuro; assim, histórias são importantes ferramentas para alcançar um futuro sagrado no qual se acredita.

LaMothe $^{61}$ estudou o desempenho da fé em histórias e rituais comuns e extraordinários, argumentando que um entendimento mais completo da dinâmica da fé emerge do exame dos processos simbólicos como pontes entre o consciente e o inconsciente. Afirmou também que o contar histórias, como atividade simbólica, cria uma resolução entre as tensões dialéticas que desafiam a fé (isso é, confiança-desconfiança, lealdade-deslealdade, crença-descrença e esperança-desespero). As histórias de uma comunidade religiosa desenvolvem significados e contextos novos para representar a crença, a confiança, a lealdade e a esperança.

\section{Álbum de recordações: um jeito de lembrar}

As religiões organizadas podem ser mais "organismos" do que "organizações", pois crescem quando passadas de uma geração à próxima como entidades vivas, dinâmicas e fortes. Valores, crenças e eventos espiritualmente significativos podem ser passados de geração a geração pela estrutura da história. O conto religioso, como resultado, pertence à religião, não ao contador; sem autor, a história é publicada vez após vez, sendo transportada pelo fôlego do contador ao ouvido (e coração) do ouvinte. O espírito vivo da religião recebe músculos e um esqueleto através da história, para que possa agir junto às pessoas que ela serve. Sabemos que a memória narrativa é forte, facilitando a retenção e a lembrança individual. A pesquisa de Schank $^{62}$ sobre a inteligência artificial, por exemplo, iluminou a memória e a inteligência humanas. Especialista em inteligência artificial, Schank concluiu que podemos informar as pessoas sobre regras gerais abstratas que derivamos de nossas experiências passadas, mas é muito difícil as pessoas aprenderem com elas. Temos dificuldade de memorizar tais abstrações, mas conseguimos lembrar mais facilmente uma boa história. Ele nos diz ainda que todo pensamento envolve alguma forma de indexação. Para assimilarmos um fato, precisamos fixá-lo em algum lugar em nossa memória. Informações às quais não há acesso não são informações. A memória, fundamental para a vitalidade de qualquer religião, é, com efeito, criada e preservada contando-se histórias.

Registrar histórias, ou fazer um álbum de recordações, é uma atividade proeminente em muitas tradições religiosas. Tribos de nativos americanos, bem como vários grupos mestiços do Havaí, são excelentes exemplos de povos que mantêm os ensinamentos espirituais de ancestrais em suas histórias. Halper ${ }^{63}$,
59. SUNWOLF. The pedagogical and persuasive effects..., op. cit.

60. BRUCHAC, J. Roots of survival: native american..., op. cit.

61. LAMOTHE, R. Performances of faith: a relation between conscious and unconscious organizations of faith (Desempenhos de fé: uma relação entre organizações conscientes e inconscientes de fé). Pastoral Psychology, 49, 363-377, 2001.

62. SCHANK, R. C. Tell me a story: a new look at real and artificial memory (Conte-me uma história: um olhar novo sobre a realidade e memória artificial). New York: Charles Scribner's Sons 1990.

63. HALPER, L. Ancestral perception with a Native American storyteller (Percepção ancestral com um contador de histórias americano nativo). Journal of Religion \& Psychical Research, 19, 232-234, 1996. 
estudando os Lakota Oglala nos Estados Unidos, encontrou um contador de histórias que lhe revelou a responsabilidade de preservar as narrativas e seu papel na manutenção da identidade espiritual de seu povo, com a alta espiritualidade contida nas histórias sempre passadas de pai para filho. A história era o tema valorizado, e não a modernização dos contos. $\mathrm{O}$ narrador se via como uma ponte entre o presente e o passado, utilizando a história para uni-los.

Uma dessas coleções ("álbum de recordações") de grande destaque para as religiões organizadas no mundo é a Bíblia, considerada um texto sagrado por três religiões: judaísmo, cristianismo e islamismo. Estudiosos modernos acreditam que a Bíblia hebraica (Tanakh) pode ter sido escrita por quatro ou cinco redatores entre 1000 a.C. e 400 a.C., em parte com base em tradições orais mais antigas. Enquanto há fortes debates sobre a seqüência e a composição dos escritos na Bíblia, há uma concordância geral de que o Novo Testamento foi redigido por diversos autores em algum momento entre 60 d.C. e 110 d.C., com seu conteúdo sendo formalizado por Atanásio da Alexandria, em 367 d.C., posteriormente canonizado em 382 d.C.

Como grandes coleções de narrativas espirituais amplamente compartilhadas, versões da Bíblia são utilizadas por contadores de histórias dentro das tradições religiosas como ferramentas fundamentais para fazer sermões e para ensinar por meio delas. O Internet Sacred Text Archive (Arquivo de Textos Sagrados da Internet) é uma fonte acessível para a comparação desses textos, contendo a versão do rei James (com links cruzados com o Easton's Bible Dictionary), os livros apócrifos, a Vulgata, o Novo Testamento grego, o Tanakh e a tradução da Jewish Publication Society da Bíblia Hebraica, publicada pela primeira vez em 1917 (Internet Sacred Text Archive, 2004).

\section{Visionário: um meio de visualizar o futuro}

Um ouvinte de uma história recebe permissão do conto para sonhar com aquilo que poderia ainda acontecer. De fato, nossos sonhos acordados são histórias contadas. Estruturas narrativas facilitam a imaginação de possibilidades futuras, bem como a contemplação de pontos hipotéticos (pensamento contrafactual ou de "e se"). Simms ${ }^{64}$ revela que à medida que os personagens de um conto de fada cruzam os limites e invadem outros âmbitos, a audiência (os ouvintes) é atraída para dentro, além dos limites da mente lógica "ao vasto espaço e à presença comunal”. O trabalho de Simms - contar histórias para a paz -, realizado com culturas de todo o mundo, levou a pesquisadora à conclusão de que a intimidade do storytelling permite que as portas da mente lógica do ouvinte se "abram para dentro", dando espaço a uma experiência de espaço de mente sem tempo e permitindo que sonhemos acordados.

Os contos do sufistas são persas, árabes e turcos. A própria palavra "su-

64. SIMMS, L. Crossing into the invisible (Cruzando no invisível). Parabola, 25, 62-68, 2000.

65. SHAH, I. Caravan of dreams (Caravana dos sonhos). London: Octagon Press, 1968. fismo" é relativamente nova, tendo sido cunhada em 1821 por um alemão; Shah $^{65}$ argumentou que nenhum sufista desconhecedor de idiomas ocidentais seria capaz de reconhecê-la. Apesar disso, o termo é utilizado aqui. O sufismo é um ensinamento esotérico dentro do islamismo que rastreia a transmissão de contos até chegar aos ensinamentos do profeta Maomé. 
Os contos de sabedoria sufistas reconhecem o poder exclusivo que as histórias têm para sugerir ao ouvinte comportamentos novos, possibilidades futuras diferentes. A sutileza é um recurso-chave: o entendimento não fica claro, a não ser que o ouvinte capte cuidadosamente o significado do conto. De modo geral, os contos sufistas são contados entre professores e alunos, não a grandes audiências nem visando entretenimento ${ }^{66}$. Os adeptos acreditam que determinada atividade mental pode produzir aquilo que é conhecido como um trabalho mental superior, levando a percepções especiais cujos mecanismos são latentes no homem comum ${ }^{67}$. Como ocorre com os nativos americanos - líderes espirituais e contadores de histórias -, os seguidores do sufismo acreditam que suas histórias instrutivas perdem algo vital quando registradas de forma escrita, uma vez que os contos orais produzem mais efeito quando destinados para um grupo ou pessoa ${ }^{68}$. Enquanto o ensinamento dos americanos nativos varia em tamanho, dependendo do contexto do storytelling, uma característica do conto de sabedoria do sufista é sua brevidade, dada a importância do impacto de uma expressão econômica.

\section{SERMÕES COM HISTÓRIAS/ENSINAMENTOS COM HISTÓRIAS: "FELIZES-PARA-SEMPRE" EM NOVAS DIREÇÕES}

\author{
"Onde está Deus?" \\ [Pergunta o contador aos ouvintes.] \\ "Não sabemos, mas as histórias sabem!" \\ [Resposta dos ouvintes ao contador.] \\ Pergunta e resposta tradicional, solicitando \\ e concedendo permissão para iniciar o storytelling.
}

Contar histórias é uma das formas mais antigas de comunicação e já foi utilizada por todas as culturas ${ }^{69}$. Apesar disso, a acessibilidade, o apelo e a variedade de vídeos e os muitos canais de filmes na TV a cabo contribuíram para distanciar os indivíduos das poderosas histórias das pessoas que os cercam - e os isolaram muito de uma consciência plena de suas próprias e ricas histórias, pessoais. A seguir, veremos três caminhos que enriqueceriam a prática e o entendimento do storytelling em tradições espirituais: como fazer novas conexões entre o contador e o ouvinte, como criar novos locais para os contos serem compartilhados e como apoiar pesquisas inovadoras sobre o contar e o ouvir histórias, de uma pessoa para outra no mundo real.

O que as histórias fazem? Afetam-nos, nada mais.

Primus St. John ${ }^{70}$
66. SUNWOLF, J. D. The pedagogical and persuasive effects..., op cit.

67. SHAH, I. Caravan of dreams..., op. cit.

68. GOLEMAN, D. Introduction (Introdução). In: FRIEDLANDER, S. Talks on Sufism..., op. cit., p. VII-IX.

69. COLLINS, R.; COOPER, P. J. The power of storytelling: teaching through storytelling $(O$ poder da narração: ensinando por narração) 2. ed. Scottsdale, AZ: Gorsuch, 1997.

70. St. JOHN, P. Dreamer (Sonhador). Pittsburgh, PA: Carnegie Mellon University Press, 1990. 


\section{Pontes de histórias: como fazer novas conexões}

Pontes de histórias que verdadeiramente conectam as pessoas umas às outras, a idéias, a valores e a novos entendimentos exigem que prestemos muita atenção ao contexto das narrativas. Scheub $b^{71}$ argumenta que a "história" é a totalidade das atividades que compõem o contar, cada uma das quais um ingrediente crucial do todo. Aqui, mostro a necessidade de prestar atenção não só ao contar a história, mas também ao conto propriamente dito.

\section{EFEITO VelCRo ${ }^{\circledR}$}

Bausch $^{72}$ argumentou sobre a importância dos contos mais curtos, como parábolas que "permanecem no subconsciente, talvez até provocando um pequeno desconforto - em uma palavra, histórias que ressonam com a condição humana”. O objetivo do contador de histórias nas tradições espirituais é o mesmo: manter-se muito próximo do espírito multifacetado do ouvinte. A história desse sucesso pode ser comparada ao efeito Velcro ${ }^{\circledR}$.

George de Mestral descobriu o segredo do Velcro ${ }^{\circledR}$ enquanto caçava nas montanhas Jura, na França, em 1941. Após arrastar-se pela mata, por entre arbustos, suas calças de lã ficaram cobertas de carrapichos que tinham incrível poder de adesão. Ele analisou esses espinhos com uma lupa e descobriu que cada um deles tinha centenas de pequenos ganchos enroscados nos laços do tecido de suas calças. Mestral construiu uma máquina para replicar esses ganchos e chamou o produto novo de Velcro ${ }^{\circledR}$, das palavras francesas velour e crochet.

A mente e a alma do ouvinte são cobertas com trilhões de minúsculos ganchos. Histórias memoráveis grudarão nesses ganchos. Quantos mais laços e ganchos, melhor. O objetivo dos contadores de histórias espirituais é o do coletor: continuamente procurar por contos que têm "poder de adesão".

As histórias não são criadas da mesma forma: uma lição é aprendida continuamente com a proliferação da televisão e com a sedução, da mídia, pela história superficial. O conto superficial de uma pessoa pode representar o alimento espiritual imprescindível da outra? Talvez. Ainda assim, há contos mais ricos a serem coletados, e comunidades de contadores de histórias das tradições religiosas devem ser estimuladas a buscá-los.

71. SCHEUB, H. Story, op. cit.

72. BAUSCH, W. J. A world of stories..., op. cit.

73. WHITE, W. R. Stories for telling..., op. cit.

\section{EFEITO DA VIVIDEZ}

O que atrai muitos contadores de histórias espirituais ao conto folclórico é a sensação da urgência moral que emitem. Tais contos estão repletos de marcas virtuais de exclamação: "Cuidado!"; "Atenção!"; "Sua escolha é importante!”; "Aqui existem dragões!"; então, o que parece ser uma escolha sem importância nenhuma freqüentemente gera conseqüências praticamente cósmicas ${ }^{73}$ : uma promessa é quebrada e o mundo desanda; uma caixa proibida é aberta e o mal escapa. 
Uma linguagem vívida traz credibilidade, deflagra a atenção e tem poder de adesão. A linguagem falada, de fato, sempre cria um efeito mais intenso no ouvinte do que a linguagem escrita recitada. $\mathrm{O}$ ritmo, as pausas, as frases, tudo é diferente. Como a linguagem escrita consiste de palavras preservadas em páginas, os contadores de histórias ficam tentados a pensar o storytelling como palavras que vêm da página, mas são faladas em voz alta. O poder de contar histórias é diferente. Mesmo quando os contos são coletados de forma textual, para que toquem o espírito devem ser transmitidos de forma coloquial, com a cadência familiar do falar diário.

Quando conversamos uns com os outros no dia-a-dia, a comunicação é rica e rítmica. Estou sugerindo que os contadores de histórias contem um conto, que eles ouçam o conto. É assim que você falaria, em uma conversa informal? Agora, como um contador de histórias que dramatiza, aprendi dos mestres contadores de histórias a abandonar minha fala textual (tão familiar para mim como é para um advogado) e a traduzir meus contos em uma fala mais vívida. Quando olhamos o texto escrito de uma história, nossa mente não consegue ver a rica oralidade das palavras. Como resultado, é difícil falar essas palavras com a vividez necessária para tocar o espírito dos outros. Encontra-se, a seguir, um excerto de uma narrativa para ilustrar isso. Primeiramente, olhe o texto escrito; pense sobre como ele soaria se você o lesse em voz alta. Depois, veja o formato oral, que estimula a mente do contador de histórias a pausar, inserir maciez, palavras de efeito, esticar palavras. Quando sua mente está "aprendendo" a partir do texto oral, uma entrega vívida é facilitada.

\section{VERSÃO ESCRITA:}

Certa vez, há muito tempo, quando a mágica ainda existia, estranhos às vezes apareciam à sua porta. Você não conhecia essas pessoas, e nunca sabia quando viriam. Depois, sua vida era alterada para sempre. Às vezes para melhor, outras vezes, não.

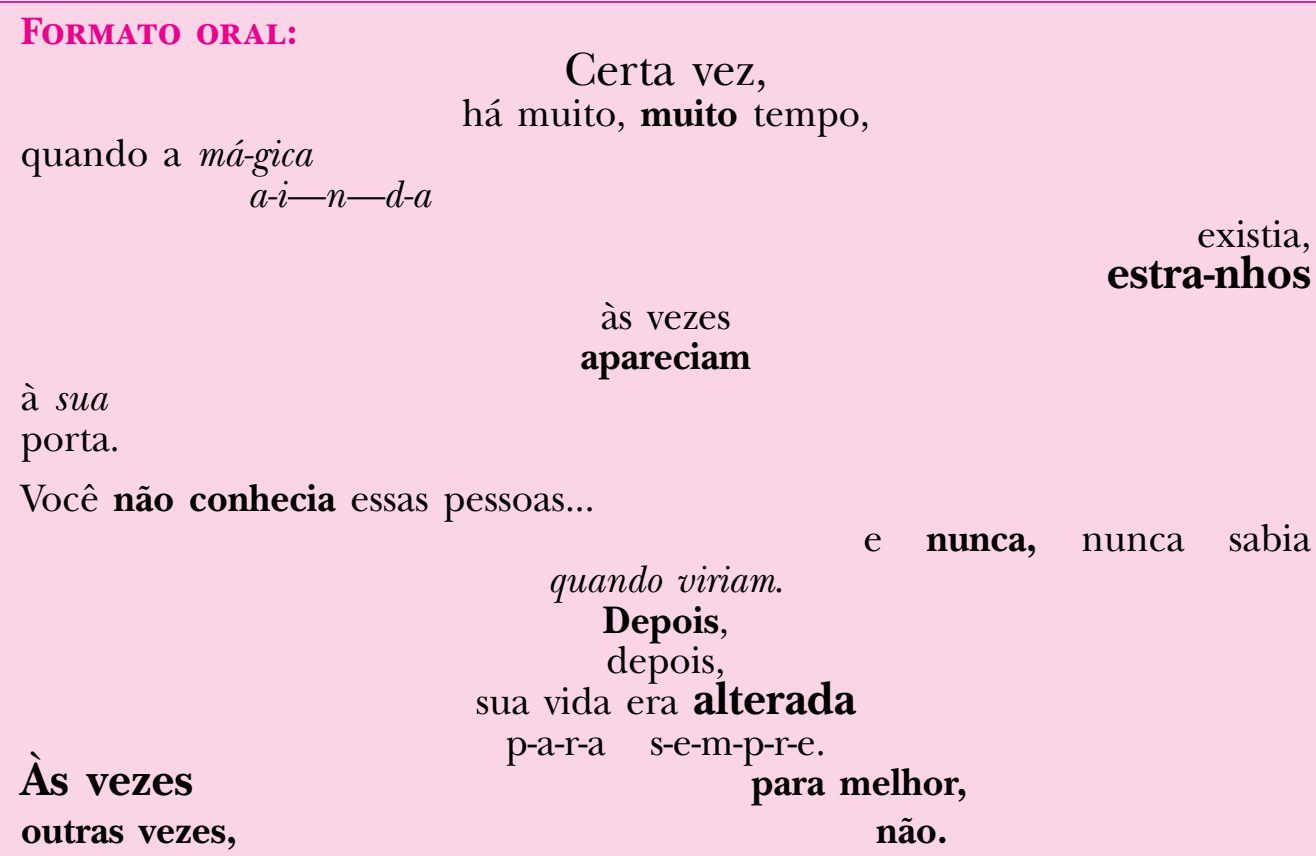


74. FREY, L. R.; SUNWOLF, J. D. A symbolic-interpretive perspective on group dynamics (Uma perspectiva interpretativo-simbólica em dinâmica de grupo). Small Group Research, 35 (3), 277-306, 2004.

75. CESARIO, S. K. Care of the Native American woman: strategies for practice, education, and research (O cuidado com a mulher americana nativa: estratégias para prática, educação e pesquisa). Journal of Obstetric, Gynecologic, and Neonatal Nursing, 30,13-19, 2001.

76. STRICKLAND, C. J. et al. Walking the journey of womanhood: Yakama Indian women and Papanicolaou (Pap) Test screening (Percorrendo a viagem da feminilidade: as mulheres índias Yakama e o exame de Papanicolau). Public Health Nursing,

13, 141-150, 1996.

77. WHITE, W. R. Spea-
Embora não exista um modo certo de criar uma versão oral a partir de um texto escrito, sua mente lembrará a diferença de forma mais completa se ele for oralizado antes de ser decorado. A segunda versão é lúdica, o que o espírito adora. As palavras são repetidas, quebradas ou amortecidas, entremeadas por breves períodos de silêncio. O contar a história é mais íntimo e até mais familiar com as coisas do dia-a-dia, alcançando diretamente a alma.

Não basta encontrar contos e estar disposto a contá-los. O compromisso com o ouvinte deve ser mais forte para o contador de histórias religiosas, para que estas "colem" um pouco melhor. No entanto, esta é uma tarefa difícil. Os ouvintes não precisam de mais histórias, mas de histórias mais bem contadas.

\section{Círculos de histórias: como criar locais}

Religiões também são organizações, formadas por grupos grandes e pequenos. A perspectiva simbólico-interpretativa das dinâmicas de grupo ${ }^{74}$ argumenta que a vitalidade de qualquer grupo depende das atividades simbólicas de seus integrantes. $\mathrm{O}$ ato de contar histórias, o ritual e os símbolos são os principais meios através dos quais os integrantes de um grupo ligam-se uns aos outros. Se expandirmos nosso pensamento além do "púlpito", há espaços mais ricos para a prática e partilha de contos e histórias religiosas. Círculos de histórias assumem uma característica coletiva de narrativa dentro de uma comunidade de fiéis. Em tais círculos, nos quais os contadores e os ouvintes reúnem-se, cria-se uma comunidade e se aproveita de sua existência. Nos Estados Unidos, onde está ocorrendo um renascimento do hábito de contar histórias tradicionais, hoje existem círculos comunitários que se reúnem mensalmente em cidades de todo o país. Os contadores narram as histórias aos ouvintes, que, por sua vez, transformam-se em contadores, à medida que um conto "puxa" o outro. Profissionais e amadores, experientes e novatos, todos se sentam juntos e se revezam no contar ou no ouvir, conforme a vontade de cada um. Poucos lugares de adoração nos Estados Unidos, entretanto, oferecem círculos de histórias para seus membros.

O poder desses círculos é reconhecido há muito tempo pela psicoterapia, por grupos de auto-ajuda e, mais recentemente, entre equipes de profissionais de saúde. O trabalho de Cesario ${ }^{75}$ com mulheres de tribos nativas norte-americanas apoiou seu argumento narrativo de que, como muitas tribos são matriarcais, o uso de tais círculos de contar histórias (compostos de cinco a 15 mulheres nativas americanas que se reúnem para compartilhar informações, dar apoio e solucionar problemas) é valorizado e visto como uma ferramenta-chave (subutilizada) para os profissionais da saúde. Estudiosos da Escola de Enfermagem da Universidade de Washington e do Centro de Saúde Indígena Yakama descobriram, ao ouvir histórias, que contos sobre doença, para as mulheres indígenas Yakama, faziam parte dos contos sobre a jornada da vida ${ }^{76}$. O câncer de colo do útero era o principal tipo de câncer entre as mulheres americanas nativas do Alasca, com alta incidência e taxas mais baixas de sobrevivência à doença entre todos os grupos étnicos dos Estados Unidos (Instituto Nacional 
do Câncer, 1993). Os líderes tribais convidaram esses estudiosos para trabalharem coletivamente com eles após a morte de três de suas mais respeitadas anciãs causada por câncer, em 1991. Como resultado do acesso aos círculos de histórias dessas mulheres, a equipe de profissionais da saúde descobriu que as anciãs tinham maior influência entre as mulheres mais jovens que estavam iniciando a jornada ("Andando nos passos da avó", p. 145); por conseqüência, fazer o exame de Papanicolau foi contado em forma de história (pelas anciãs) como uma parte importante de se tornar mulher, muito diferente do método ocidental de orientação sobre saúde, que se baseia no uso de fitas de vídeo, aulas e impressos.

A jornada da alma também faz uso dos círculos de histórias. Dentro das igrejas, esses círculos oferecem estruturas simples e gratuitas que proporcionam um lugar para todos os cinco aspectos funcionais para o desenvolvimento da partilha de histórias. Nutrir e manter os fiéis, enquanto se vai ao encontro de novos adeptos, é um desafio para as religiões organizadas. Os círculos de histórias podem ajudar ao fazer que se reúnam os novos e os antigos membros da congregação, jovens e velhos, homens e mulheres, pessoas de origens étnicas diversas, aqueles que estão carentes, bem como os que têm algo a oferecer. Em tais círculos as reuniões acontecem tanto antes dos cultos formais quanto depois deles, sintonizadas com eventos especiais ou isoladamente, em locais fechados ou ao ar livre, em casas ou hospitais. White ${ }^{77}$ descreve seu treinamento inicial de pregador, observando que, como diretor de grupos eclesiais em áreas rurais, por anos suas "salas" ficavam ao redor de fogueiras ou sob as árvores.

Como a organização do círculo é flexível, este diminui ou expande-se à medida que as pessoas chegam ou partem. Embora um horário de início seja necessário, o círculo termina quando todos os ouvintes cansam de ouvir; esse horário pode ser medido em minutos ou horas, pois objetivos espirituais não dependem do relógio. Um círculo de histórias de 20 minutos para novos membros seria, de fato, um tesouro para antigos participantes. Tratando-se de culturas como aquelas descritas anteriormente, que têm círculos de histórias de caráter tradicional e possuem modelos prontamente acessíveis, o Homo narrans gosta de participar de círculos de histórias sempre que tem oportunidade.

\section{Conhecimento de histórias: como expandir nossa pesquisa}

É surpreendente observar que existe pouco conhecimento acadêmico sobre o efeito do ato de contar histórias. Em sua maioria, esse trabalho concentra-se nas estruturas, funções e nas variações culturais do processo. O efeito de ouvir, entretanto, é de grande interesse no contexto religioso e, além disso, está dentro do domínio dos estudiosos da comunicação. Emissor, mensagem, receptor, ruído, contexto são todas variáveis que os pesquisadores de comunicação conseguem investigar de modo único a partir de várias perspectivas teóricas.

Além de uma falta de atenção acadêmica ao ouvinte de histórias, poucos pesquisadores investigaram os efeitos de contar histórias dentro de tradições

king in stories..., op. cit. 
culturais. As histórias contadas, o objetivo do contador, as histórias da perspectiva do professor religioso, tudo é bem documentado. A maneira como um conto é recebido por um ouvinte em especial, se a necessidade ou o objetivo era espiritual ou uma questão de fé, entretanto, foi deixada de lado. Relatos informativos e ensaios bem pensados de pregadores sugerem, porém, que o efeito da história é poderoso entre os ouvintes. White ${ }^{78}$ descreve sua própria jornada como pregador: "Vários anos e um diploma de teologia mais tarde, descobri a alegria da história em minhas congregações rurais no sul de Wisconsin. Naqueles cultos sérios e rígidos, a história era uma ocasião de alívio e deleite. Quando eu começava a narrar alguns de meus contos, as pessoas descruzavam os braços e se curvavam para a frente, as sobrancelhas subiam. Embora parecessem tolerar os sermões, elas adoravam as histórias".

White, um ministro que estimula o storytelling, fala não apenas para pregadores e professores, mas para estudiosos também, quando compartilha de sua convicção de que mensagens religiosas, para conseguirem "penetrar nas mentes das pessoas", devem estar repletas de figuras que estimulem as pessoas a se abrirem a elas.

Quando examinamos os efeitos de contar histórias religiosas, sempre procuramos por uma comunicação. Precisamos entender mais sobre a experiência do ouvinte da miríade de contos que estão sendo narrados em todo o mundo nos contextos espirituais.

Histórias são alimentos mágicos que são oferecidos aos outros e, quando recebidas pelo coração, elas nunca acabam.

Fishes and Loaves [Peixes e Pães] 
Resumo: Histórias estão entre as nossas unidades mais básicas de comunicação. Somos socializados através da narratividade, embora possamos sê-lo também por meio da racionalidade. O papel das histórias em uma explicação social foi analisado em campos tão diversos como a psicologia, sociolingüística, ciências políticas, história, antropologia, direito e comunicações. Os seres humanos pensam, percebem, imaginam e fazem escolhas morais de acordo com as estruturas de narrativa. Embora os efeitos de compartilhar narrativas tenham sido bem documentados entre crianças em ambientes educacionais, como portadoras de cultura, e entre aqueles que estão doentes, relativamente pouca atenção acadêmica direciona-se à questão de como ouvir as narrativas afeta os membros de tradições e comunidades espirituais. Os próprios contadores de histórias, entretanto, há muito tempo reconhecem o poder que as narrativas têm para transportar os ouvintes da dor do momento a um "e todos viveram felizes para sempre". Os contos orais vieram antes dos textos escritos em todas as tradições religiosas. Para enfocar a discussão, são esclarecidos três termos: espiritualidade, fé e religião. Aqui, uma interseção é oferecida para enquadrar a discussão de histórias; dá-se atenção ao uso de histórias orais dentro de práticas espirituais, de metas que geram fé e dentro de instituições religiosas. As pessoas têm uma necessidade básica pela espiritualidade para ajudá-las a dar sentido ao mundo, enquadrar suas escolhas sobre em que crer ou rejeitar, determinar o que valorizar e para guiar escolhas comportamentais. As religiões oferecem uma estrutura, um suporte e uma fundação mais específicas para a necessidade espiritual central. $\mathrm{O}$ ato de contar histórias é uma ferramenta vital para alcançar essas necessidades e metas.

Palavras-chave: contos orais, contador de histórias, narrativas, tradições espirituais, folclore.
Abstract: Stories are among our most basic units of communication. We are socialized through narrativity, though we can be educated through rationality. The role of stories in a social explanation was analyzed in fields as diverse as psychology, sociolinguistics, political sciences, history, anthropology, law and communication. Human beings think, perceive, imagine and make moral choices according to their narrative structures. However the effects of sharing narratives have been well documented for children in educative environments, as culture carriers, and for the sick people, relatively small academic attention was focused on how listening to narratives affects the members of traditions and spiritual communities. Though, storytellers themselves have recognized for long time the power of narratives to take the listeners from the pain in a moment to the "and they all lived happily ever after". Oral tales came before written texts in all spiritual traditions. To focus the discussion, three terms are clarified: spirituality, faith and religion. Here, an intersection is given to frame the discussion of stories: attention is given to the use of oral stories inside spiritual practices, to goals that generate faith and to religious institutions. People have a basic necessity of spirituality to help them in giving sense to the world and frame their choice on what to believe or reject, determine what to valorize and guide to behavioral choices. Religions offer more specific structure, support and foundation for a central spiritual need. Storytelling is a vital tool for reaching these necessities and goals.

Keywords: oral tales, storyteller, narratives, spiritual traditions, folklore. 